\title{
Risk of myocardial infarction and overall mortality in survivors of venous thromboembolism
}

\author{
Consuelo Huerta*1, Saga Johansson ${ }^{2,3}$, Mari-Ann Wallander ${ }^{4}$ and Luis A \\ García Rodríguez ${ }^{1}$
}

Address: ${ }^{1}$ Spanish Centre for Pharmacoepidemiologic Research (CEIFE), Madrid, Spain, ${ }^{2}$ AstraZeneca R\&D Mölndal, Sweden, ${ }^{3}$ Institute of Medicine, Sahlgrenska Academy, Gothenburg University, Sweden and ${ }^{4}$ Department of Public Health and Caring Science, Uppsala University, Sweden

Email: Consuelo Huerta* - chuerta@ceife.es; Saga Johansson - Saga.Johansson@astrazeneca.com; Mari-Ann Wallander - MariAnn.Wallander@astrazeneca.com; Luis A García Rodríguez - lagarcia@ceife.es

* Corresponding author

Published: 18 August 2008

Thrombosis Journal 2008, 6:10 doi:10.1186/1477-9560-6-10
Received: 8 April 2008

Accepted: 18 August 2008

This article is available from: http://www.thrombosisjournal.com/content/6/1/10

(c) 2008 Huerta et al; licensee BioMed Central Ltd.

This is an Open Access article distributed under the terms of the Creative Commons Attribution License (http://creativecommons.org/licenses/by/2.0), which permits unrestricted use, distribution, and reproduction in any medium, provided the original work is properly cited.

\begin{abstract}
Background: Venous thromboembolism (VTE) and thromboembolic arterial diseases are usually considered to be distinct entities, but there is evidence to suggest that these disorders may be linked. The aim of this study was to determine whether a diagnosis of VTE increases the long-term risk of myocardial infarction (MI).
\end{abstract}

Methods: The incidence rate $(\mathrm{IR})$ and relative risk (RR) of $\mathrm{MI}$ in a cohort of patients with a diagnosis of VTE $(n=4890)$ compared with that of a control cohort without prior VTE $(n=43$ 382) were evaluated in the UK General Practice Research Database (GPRD). Death during followup was also determined. Patients were followed for up to 8 years (mean of 3 years).

Results: The IR of MI per 1000 person-years was 4.1 (95\% Cl: 3.I-5.3) for the VTE cohort and 3.5 (95\% Cl: 3.2-3.8) for the control cohort. The IR of MI was highest in the first year after the VTE episode, but overall differences between the two cohorts were not significant (RR of MI associated with VTE: I.2; 95\% Cl: 0.9-1.6). The risk of death was higher in the VTE cohort than the control cohort, even after adjustment for cancer, heart failure and ischaemic heart disease (RR: 2.4; 95\% Cl: 2.2-2.6), particularly during the first year after VTE (RR: 3.8; 95\% Cl: 3.4-4.3).

Conclusion: A VTE episode does not significantly increase the risk of MI, but does increase the risk of death, particularly in the first year following VTE diagnosis.

\section{Background}

Venous thromboembolism (VTE), usually manifested as deep vein thrombosis (DVT) or pulmonary embolism (PE), is usually considered to be a distinct entity from the thromboembolic arterial diseases, such as myocardial infarction (MI), peripheral artery disease and ischaemic stroke. However, both VTE and thromboembolic arterial diseases involve the formation of clots within blood vessels, and so may be linked. Recent studies have investigated the incidence of arterial events in patients with VTE, and have reported data suggesting that there may be a positive association between VTE and thromboembolic arte- 
rial disease [1-3]. However, these studies either lacked a suitable control group or involved relatively small numbers of patients.

To determine whether a diagnosis of VTE is associated with an increased risk of arterial disease, the incidence of arterial disease in patients with a prior VTE should be compared with that in matched controls without a history of VTE. In this study we aimed to perform such an analysis by assessing the risk of MI in patients with a VTE diagnosis and control patients without VTE using data recorded prospectively from the UK General Practice Research Database. We also aimed to estimate the overall long-term mortality among patients with VTE during a long-term follow-up period in comparison with that of the control population without VTE.

\section{Methods}

\section{Data source}

The GPRD contains computerized information entered by primary care physicians (PCPs) in the UK. The vast majority of the UK population is registered with a PCP. About 1500 PCPs participate in the GPRD, covering a population of around 3 million individuals, who are broadly representative of the UK population. The PCPs hold the complete medical record of registered individuals, including demographic data, all medical diagnoses, consultant and hospital referrals, and a record of all prescriptions issued. Prescriptions are generated directly from the PCP's computer and entered into the patient's computerized file. All the information is recorded by PCPs during consultations in a standard fashion and practices regularly anonymize and send these data to the Medicines and Healthcare Products Regulatory Agency (MHRA), which is in charge of quality control and management of the data for use in research projects. Several validation studies have shown the accuracy and completeness of data in the GPRD [4,5]. Previous studies have also confirmed the validity of using the GPRD for epidemiological research in the field of DVT and PE [6-10].

\section{Study cohorts}

The source population included individuals aged 20-79 years enrolled with a participating PCP for more than 2 years during 1 January 1994 to 31 December 2000, without a previously recorded diagnosis of VTE, as described in a previous cohort study of the natural history of VTE [11]. The resulting source population consisted of 1856206 patients, and the first day of meeting these eligibility criteria was used as each individual's start date. Of this source population, 6550 patients had a first recorded diagnosis of VTE from the individual's start date until 31 December 2000. The validation (positive predictive value) of a VTE diagnosis in the GPRD has been described previously: a questionnaire was sent to PCPs for a random sample of
$5 \%$ of patients with a record of VTE and, after reviewing these questionnaires, the diagnosis of VTE was confirmed in $94 \%$ of cases [11]. Moreover, we previously reported that the overall incidence rate of VTE in the study cohort was 74.5 per 100000 person-years [11]. In other epidemiological studies, the incidence of VTE ranged from 71 to 117 case per 100000 of the population per year (standardized for age and sex) [12].

We classified VTE episodes as idiopathic if they occurred in the absence of the following transient risk factors: fracture, surgery, pregnancy or childbirth, or any hospitalization (all occurring in the 3-month period before VTE); cancer in the year before VTE; or use of hormone replacement therapy or oral contraceptives in the 6 months before the date of the VTE episode. We considered all other cases of VTE to be secondary, in a similar manner to other studies $[1,13]$.

A control cohort was also identified. For this, 50000 individuals without a VTE diagnosis were randomly sampled from the source population and matched by age, sex and calendar year to the VTE cohort.

\section{Definition of clinical endpoints \\ Myocardial infarction}

Patients with a history of ischaemic heart disease prior to their start date were excluded from both VTE and control cohorts for the analysis of the risk of MI following a VTE, as a history of ischaemic heart disease could mask the influence of VTE on a subsequent MI. Each individual's start date was the date of diagnosis of VTE in the VTE cohort and a random date within the study period for the control cohort. Follow up started a month after the start date in order to exclude patients dying due to the initial episode of VTE. Finally, there were 4890 patients in the VTE cohort and 43382 patients in the control cohort.

Patients in both cohorts were then followed up until one of the following endpoints was reached: a recorded code of MI, age of 80 years, death or the end of the study period (31 December 2002). We manually reviewed the computerized profiles of all patients identified with a code of MI, and all deaths. We considered MI cases to be patients whose diagnosis was confirmed by a letter from a consultant cardiologist or on hospital discharge. We also considered as cases: those who died from coronary heart disease (CHD); patients with post-mortem evidence of a recent MI or a recent coronary artery occlusion; patients with ante-mortem evidence of CHD in the absence of another cause of death; and patients for whom CHD was recorded as the underlying cause of death. We did not contact PCPs for further confirmation of the diagnosis of $\mathrm{MI}$, as our experience from a previous study of MI in the GPRD has shown that case ascertainment after manual review of the 
computerized information supports our case definition in more than $90 \%$ of instances [14].

\section{Mortality}

For the mortality analysis, individuals with a history of ischaemic heart disease prior to the start date were not excluded, but follow-up was started 1 month after the episode of VTE as before. (Data for patients who died within the first month of the VTE diagnosis have been presented elsewhere [11].) The VTE cohort consisted of 5801 patients and the control cohort consisted of 48399 patients. Patients were followed until death, age of 80 years or the end of the study period (31 December 2002).

\section{Analysis of MI risk}

Relative risk and Kaplan-Meier survival analysis

Estimates of MI occurrence (with 95\% CI) were calculated for the VTE and control cohorts. Individuals alive at the end of the study period were regarded as censored from that date, while individuals with their last practice visit before the end of the study were regarded as censored from the date of their last practice visit. The cumulative hazard of MI was calculated using a Kaplan-Meier survival analysis. Cox proportional hazards regression was used to estimate the relative risk (RR) and 95\% confidence intervals of MI in the VTE cohort compared with the control cohort (overall and according to type of VTE). Variables included in the multivariate model were the presence of heart failure and hypertension, as well as frequencymatched variables (age, sex, and calendar year).

\section{Analysis of mortality}

Deaths from any cause during the follow-up period were analysed using Kaplan-Meier life-tables to compare survival between patients with or without VTE. Cox proportional hazards regression was used to estimate the RR and 95\% CI of death in the VTE cohort compared with the comparison cohort. Variables included in the multivariate model were the presence of cancer or heart failure as well as the frequency-matched variables (age, sex and calendar year). All statistical analyses were conducted using STATA (version 8.2; Stata Corporation, College Station, Texas, USA).

\section{Results}

\section{Risk of myocardial infarction}

The incidence and risk of MI were determined for the cohort of VTE patients $(n=4890)$ and the control cohort $(n=43382)$, in order to provide an estimate of the RR of MI following VTE. The age distribution in the two cohorts was successfully matched, with $12.3 \%$ of both cohorts aged 20-39 years, 33.3\% aged 40-59 years, 27.1\% aged 60-69 years and $27.3 \%$ aged 70 years or older. During the mean follow-up period of 3 years (range: 3-8 years; median: 3 years), MI occurred in 55 patients from the VTE cohort and 472 patients from the control cohort. Thus the incidence rate (IR) of MI per 1000 person-years was 4.1 (95\% CI: 3.1-5.3) for the VTE cohort and 3.5 (95\% CI: 3.2-3.8) for the control cohort. The difference between the two groups was not significant, as shown by the RR of MI (RR: 1.2; 95\% CI: 0.9-1.6). The incidence rates of MI were within the range reported in previous populationbased studies in the UK (2.73-8.23 and 0.66-2.56 per 1000 person-years in men and women, respectively $[15,16])$.

The IR of MI increased with age in both cohorts (see Figure $1)$. Although the IR of MI was numerically greater in the VTE cohort than the control cohort for those aged 60-69 years or at least 70 years, determination of RR indicated that these differences were not significant (RR: $1.3 ; 95 \%$ CI: $0.8-2.0$ for patients aged 60-69 years, RR: $1.4 ; 95 \%$ CI: $0.9-2.0$ for those aged 70 years or more). The cumulative proportion of patients diagnosed with MI over time for the two cohorts is shown in Figure 2. This analysis showed that the cumulative proportion of patients with MI was slightly greater in the VTE cohort than the control cohort in the first year, but this difference narrowed in years 2-4. Indeed, the increased risk of MI in the VTE cohort compared with the control cohort in the first year was of borderline significance (adjusted RR: 1.6; 95\% CI: 1.0-2.5). After the first year, the adjusted RR of MI associated with VTE fell to 1.0 (95\% CI: 0.7-1.5).

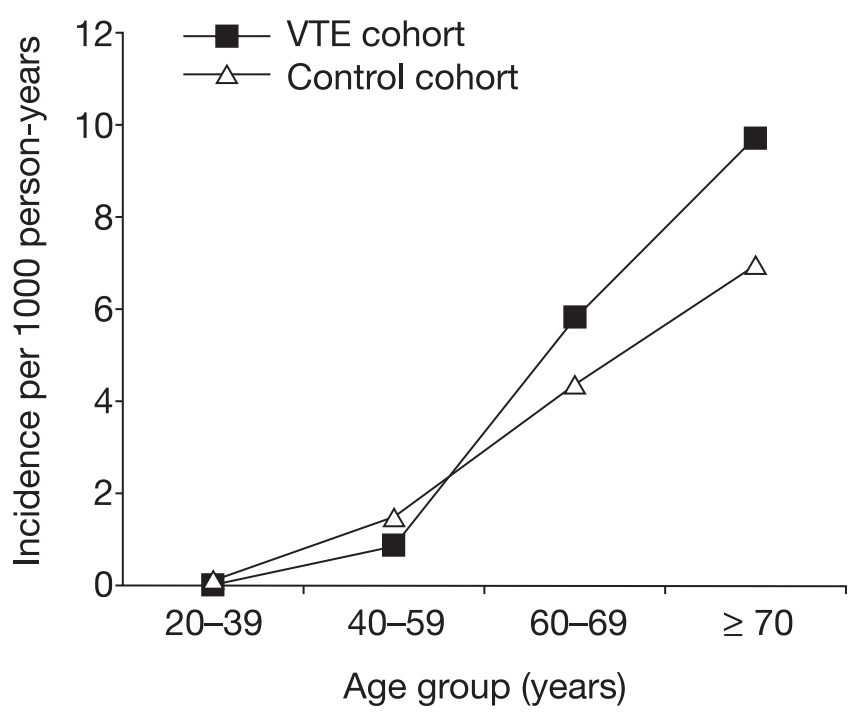

Figure I

Incidence rate (IR) and relative risk (RR) of myocardial infarction in the venous thromboembolism (VTE) cohort and control cohort according to age. 


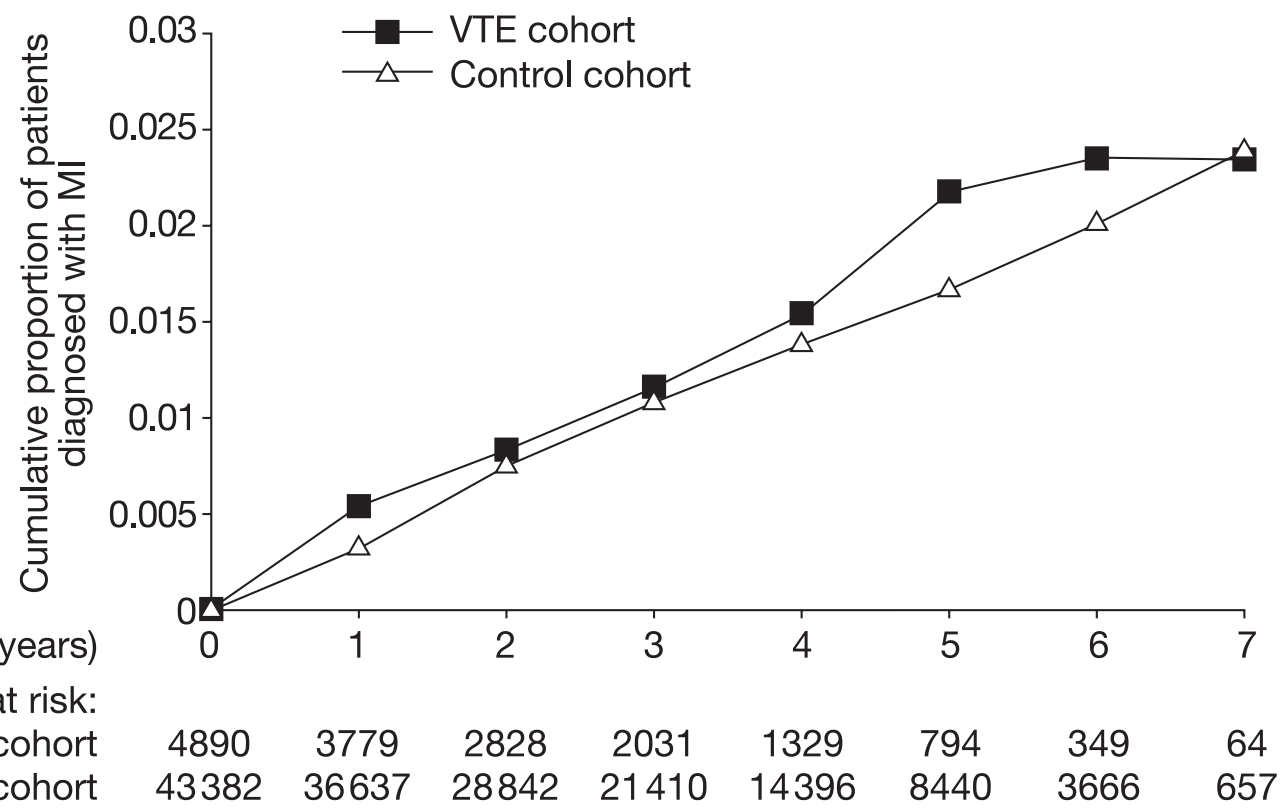

Figure 2

Cumulative proportion of patients diagnosed with myocardial infarction (MI) in the venous thromboembolism (VTE) cohort and control cohort over time (log-rank test $>0.05$ ).

Further analysis of the risk of MI in the VTE cohort compared with the control cohort for the first year showed that the excess risk was of borderline significance in patients aged between 60 and 69 years (RR: 2.0; 95\% CI: $1.0-4.0)$ and insignificant in the younger age group (4059 years of age, RR: $0.70 ; 95 \% \mathrm{CI}: 0.1-5.3)$ and older age group ( $\geq 70$ years, RR: $1.5 ; 95 \% \mathrm{CI}: 0.8-2.9$ ). The risk of MI in the VTE cohort, however, was similar for patients who had had DVT $(\mathrm{n}=33)$ and for patients who had had PE with or without DVT $(\mathrm{n}=22)$ (Table 1$)$. The risk of MI was also similar regardless of whether the VTE was idiopathic or secondary (Table 1).

\section{Mortality}

During the total follow-up period of 8 years, 3088 patients died: 2266 of 48399 in the control cohort and 822 of 5801 in the VTE cohort. Overall mortality was, therefore, higher in the VTE cohort $(14.2 \% ; 49.5$ per 1000 person-years) than the control cohort (4.7\%; 14.5 per 1000 person-years) (Figure 3). After adjustment for the presence of cancer, ischaemic heart disease and heart failure, the RR of death during this 8-year period in the VTE cohort compared with the control cohort was 2.4 (95\% CI: 2.2-2.6). When we re-analyzed the mortality findings after excluding patients with a history of ischaemic heart disease to allow comparison with the incidence of MI in these cohorts, the mortality rates dropped to 47.4 and

Table I: Incidence rate and relative risk of myocardial infarction in the venous thromboembolism cohort compared with the control cohort in the first year of follow up.

\begin{tabular}{lccc}
\hline & $\begin{array}{c}\text { Myocardial } \\
\text { infarction } \\
\text { cases }(\mathbf{n}=\mathbf{~ 1 5 9 )}\end{array}$ & $\begin{array}{c}\text { Incidence } \\
\text { rate per I000 } \\
\text { person-years }\end{array}$ & $\begin{array}{c}\text { Relative risk } \\
\mathbf{( 9 5 \%} \mathbf{C l})^{\mathbf{a}}\end{array}$ \\
\hline Control cohort $(\mathbf{n}=\mathbf{4 3} \mathbf{3 8 2})$ & 136 & $3.4(2.9-4.0)$ & 1 \\
Venous thromboembolism cohort $(\mathbf{n}=\mathbf{4 8 9 0 )}$ & 23 & & \\
Deep vein thrombosis & 15 & $5.7(3.4-9.4)$ & $1.7(1.0-2.9)$ \\
Pulmonary embolism & 8 & $4.8(2.4-9.6)$ & $1.5(0.7-3.1)$ \\
Secondary venous thromboembolism & 13 & $5.2(3.0-8.9)$ & $1.6(1.0-2.8)$ \\
Idiopathic venous thromboembolism & 10 & $5.6(3.0-10.4)$ & $1.6(0.8-3.2)$ \\
\hline
\end{tabular}

aAdjusted relative risk derived from Cox regression models including sex, age, calendar year, heart failure, hypertension, and smoking. 


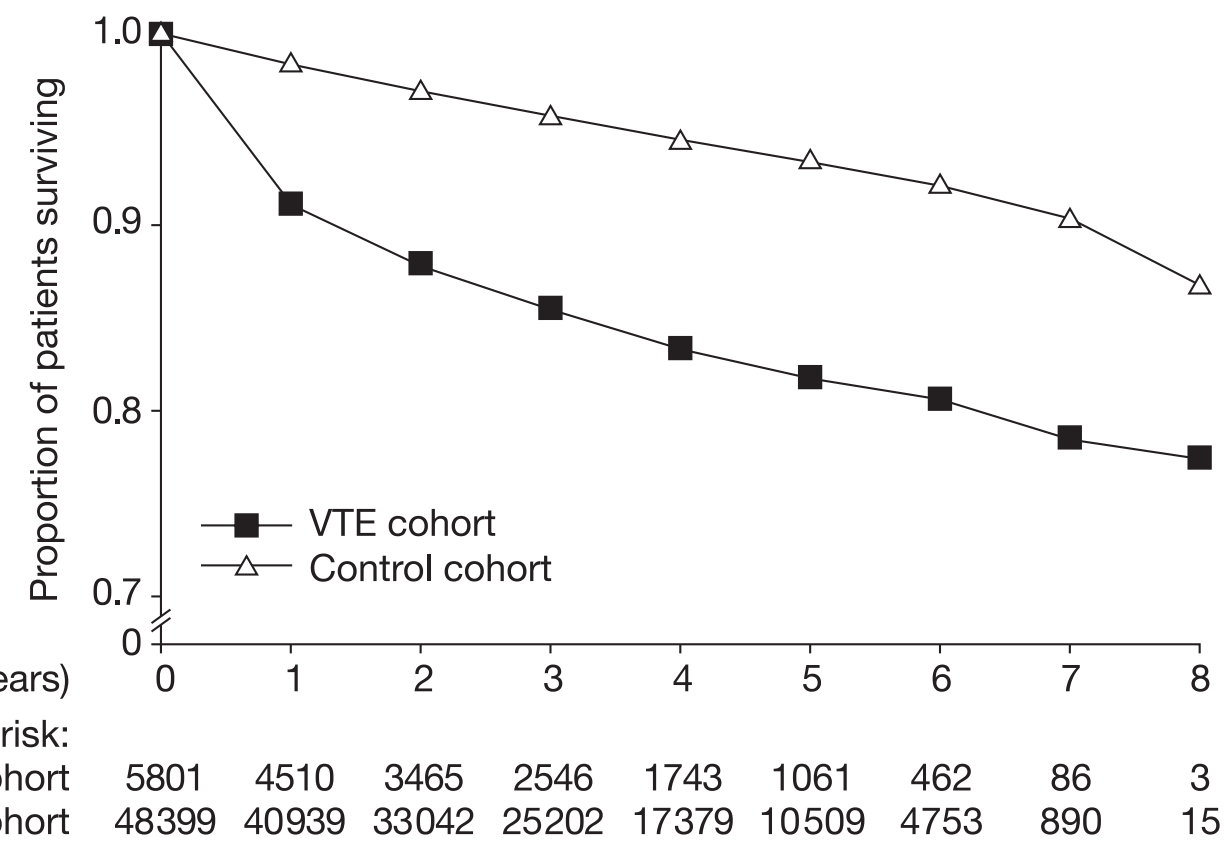

*Log-rank $=1005.25 ; p<0.005$

\section{Figure 3}

Kaplan-Meier survival curves for venous thromboembolism (VTE) cohort and control cohort (*log-rank = 1005.25; $\mathrm{p}<0.005)$.

12.1 per 1000 person-years in the VTE and control cohorts, respectively.

The increased risk of death associated with VTE was much greater in the first year after VTE diagnosis (RR: 3.8; 95\% CI: 3.4-4.3) than in subsequent years (RR: 1.6; 95\% CI: 1.8-1.4) (Table 2). The risk of death in the first year was also greater in patients with a diagnosis of DVT (RR: 4.4; 95\% CI: 3.9-5.1) than in those with a diagnosis of PE (RR: 2.9; 95\% CI: 2.5-3.5) (Table 2). Compared with the control group, mortality was increased in patients aged 20-59 years (RR: $10.5 ; 95 \% \mathrm{CI}: 7.3-15.1$ ) and at least 60 years (RR: $3.1 ; 95 \%$ CI: $2.7-3.6$ ).

Causes of death for patients dying within the first year of follow up are shown in Table 3 . The main cause of death was cancer in both groups, but the percentage of patients dying from cancer was almost two-fold higher in the VTE group ( 56.0 vs. $29.6 \%$ ). Conversely, the proportion of patients dying from CHD was approximately two-fold greater in the control cohort than the VTE cohort.

Table 2: Mortality and relative risk of $\mathrm{Ml}$ in the venous thromboembolism cohort compared with the control cohort, according to year of follow up.

\begin{tabular}{|c|c|c|c|c|c|c|}
\hline & \multicolumn{3}{|c|}{ First year } & \multicolumn{3}{|c|}{ After I year } \\
\hline & $\begin{array}{l}\text { Deaths } \\
(n=1216)\end{array}$ & $\begin{array}{l}\text { Mortality/l } 000 \\
\text { person-years } \\
(95 \% \mathrm{CI})\end{array}$ & $\begin{array}{c}\text { RR }(95 \% \\
\text { Cl) }\end{array}$ & $\begin{array}{c}\text { Deaths } \\
(\mathrm{n}=1872)\end{array}$ & $\begin{array}{c}\text { Mortality/l } 000 \\
\text { person-years } \\
(95 \% \mathrm{Cl})\end{array}$ & $\operatorname{RR}(95 \% \mathrm{Cl})^{\mathrm{a}}$ \\
\hline Control cohort & 716 & $16.0(\mid 4.9-17.1)$ & I & 1550 & $13.9(13.2-14.6)$ & 1 \\
\hline All VTE cases & 500 & $97.8(89.6-106.8)$ & $3.8(3.4-4.3)$ & 322 & $28.1(25.2-3 \mid .3)$ & $1.6(1.4-1.8)$ \\
\hline DVT & 344 & $113.4(102.0-126.1)$ & $4.4(3.9-5.1)$ & 186 & $27.7(24.0-32.0)$ & $1.6(1.4-1.9)$ \\
\hline $\mathrm{PE}$ & 156 & $75.1(64.2-87.9)$ & $2.9(2.5-3.5)$ & 136 & $28.7(24.2-33.9)$ & $1.6(1.3-1.9)$ \\
\hline
\end{tabular}

$\mathrm{Cl}$, confidence interval; DVT, deep vein thrombosis; PE, pulmonary embolism; RR, relative risk; VTE, venous thromboembolism.

aRelative risk estimated by Cox regression adjusted for age, sex, calendar year, consultations in the previous year, cancer, heart failure and ischaemic heart disease. 
Table 3: Distribution of causes of death in patients dying during the II months of follow up in patients with VTE surviving the first month after VTE diagnosis in comparison with control cohort.

\begin{tabular}{lcc}
\hline Cause of death & $\begin{array}{c}\text { VTE cohort (n= 500) } \\
\mathbf{n}(\%)\end{array}$ & $\begin{array}{c}\text { Control cohort (n= 7I6) } \\
\mathbf{n}(\%)\end{array}$ \\
\hline Coronary heart disease (CHD) & $49(9.8)$ & $153(21.4)$ \\
Other cardiovascular and cerebrovascular diseases & $63(12.6)$ & $107(14.9)$ \\
Cancer & $280(56.0)$ & $212(29.6)$ \\
Other non-cardiovascular diseases (respiratory, digestive, urinary, other) & $47(9.4)$ & $129(18.0)$ \\
Unknown & $61(12.2)$ & $115(16.1)$ \\
\hline
\end{tabular}

\section{Discussion}

The results of this study suggest that a first VTE episode does not increase the risk of MI. These results were similar, regardless of VTE type (DVT or PE), or whether VTE was idiopathic or secondary. However, while we did not observe a significant increase in the risk of MI following VTE (RR: 1.2 with a lower 95\% CI below 1.0), the upper 95\% confidence interval of 1.6 means that an increased risk of MI following VTE cannot be safely excluded on the basis of our results.

These results contrast with several, much smaller, studies that have pointed towards an association between VTE and thromboembolic arterial disease. Case-control studies have reported a significantly higher prevalence of carotid plaques in patients with DVT $(n=299)$ [17] and a significantly higher incidence of coronary artery calcification in patients with idiopathic VTE $(\mathrm{n}=89)$ compared with matched controls lacking VTE [18]. Moreover, Bova and colleagues found a significantly higher risk of arterial events in 151 patients with VTE compared with 151 controls (HR 2.9; 95\% CI: 1.1-7.6) [13]. Recently, a cohort study reported the risk of $\mathrm{MI}$ to be increased by $60 \%$ in the first year after an episode of VTE, with a progressive decline during the subsequent 20 years [19]. As the present study includes nearly 5000 patients with VTE and a control cohort without prior VTE $(n=43382)$, our conclusion that VTE is not associated with a major increased risk of subsequent $\mathrm{MI}$ is likely to be authoritative.

The conclusions of our study contradict those of Bova and colleagues [13], but this may reflect, in part, differences in the criteria used to identify patients with VTE and the arterial events used as endpoints. Moreover the latter study was comparatively small, though to our knowledge it is the only study other than ours and the aforementioned study by Hong et al. in 89 patients with VTE [18] to compare patients with VTE with controls taken from a general population without VTE. Other studies investigating VTE as a risk factor for cardiovascular events did not include a control group without VTE. For example, two studies compared patients with idiopathic VTE with patients diagnosed with secondary VTE $[1,2]$, and one investigated the long-term effects of 6 weeks vs 6 months of anticoagulation treatment on patients with VTE [3]. Given the large number of patients with first VTE $(n=4890)$ in our study, it seems unlikely that VTE is associated with a subsequent MI for patients without a history of ischaemic heart disease.

In contrast to the conflicting results surrounding the association between DVT and cardiovascular disease, it is well recognised that there is an increased mortality after VTE [3]. The present study showed that a first diagnosis of VTE was associated with significantly increased mortality in those who survived the first month following the VTE event, particularly in the subsequent 11 months after VTE diagnosis. This risk was greatest in patients with DVT rather than $\mathrm{PE}$, and in younger patients rather than the elderly. Previous studies have shown that mortality is highest immediately after VTE in patients with PE, and then decreases over the following year $[20,21]$. However, to our knowledge, few studies have investigated mortality in patients for prolonged periods after VTE. Our study therefore provides important data on long-term mortality following a VTE event in a large number of patients $(\mathrm{n}=$ 5801). These findings complement those from a previous study in the same cohort of patients with VTE which reported patient mortality in the first month after VTE [11].

The present study showed that, during the first year after VTE, cancer was the most frequent cause of death in VTE patients surviving the first month. Cancer is a well-known risk factor for VTE and death from VTE [3,11,22-24], with the mortality seemingly independent of whether the cancer diagnosis is made before or after VTE diagnosis [24]. As such, cancer (and death because of cancer) is likely to be more common in the VTE cohort. Secondly, the data for this period may be skewed somewhat, as the 1-month period after VTE is omitted. During this 1-month period there were more deaths due to cardiovascular causes than cancer, as has been reported previously [11]. Deaths during the 1-month period after VTE were largely due to PE, rather than DVT, with the 1-month death rate of $1.4 \%$ 
after an episode of DVT and $22.6 \%$ after PE with or without DVT [11].

The 8-year risk of death in patients surviving the first month after VTE is higher than that in patients without VTE, even after adjustment for cancer, heart failure and ischaemic heart disease. Because of the likely multiple comorbid diseases and risk factors in the predominantly elderly population with VTE in this study, we should be cautious about the reasons for this excess mortality. Thus, although the 8-year risk of death in patients surviving 1month after VTE is higher than that in patients without VTE, it is difficult to say whether this increased risk arises from VTE itself or other underlying conditions or risk factors.

This study has a number of important strengths. Patients were drawn from a large primary care database representative of the UK population and spanning a wide age range, and representing a study population that is an order of magnitude larger than previous studies investigating potential risk factors and complications of VTE $[13,17,18,25-29]$. Cases of VTE were classified according to whether they were DVT or PE, and also if they were idiopathic or secondary, allowing analysis of possible differences between the types of VTE. VTE cases in a random sample were also identified and validated with a confirmation rate of over 94\% [11]. We excluded information bias since information was collected in the same manner for VTE and comparison patients, and information collection in VTE cases was blinded to the later occurrence of MI. Using MI, a major clinical event, as the cardiovascular endpoint was advantageous as previous studies using the GPRD have shown the validity of using codes for MI $[14,30]$. Limitations of the study include the fact that it only involved a UK population sample and that patients included in the analysis of MI risk may have had subclinical cardiovascular disease prior to the start date of the study. Patients may also have had VTE or MI prior to enrolment in the GPRD, which would not have been systematically recorded. In addition, the limited number of MI cases in the VTE cohort (55) means that the study is not powered to detect modest but potentially clinically important elevations in the incidence rate of MI.

\section{Conclusion}

In conclusion, our data show that a diagnosis of VTE does not increase the risk of MI in comparison with a control cohort drawn from the general population of the UK. There was some suggestion that the risk of MI may be increased in elderly patients with VTE during the first year following the diagnosis of VTE, but this increase was not statistically significant. While the risk of MI is not increased, patients who survive the first month after a VTE event were significantly more likely than controls to die in the subsequent 8 years. This increased risk is particularly marked over the first year following a VTE. Further studies may thus be required to investigate the causes of death following VTE in more detail, and thus determine how best to reduce mortality in patients after a first VTE event.

\section{Competing interests}

This study was funded by a research grant from AstraZeneca R\&D Mölndal, Sweden. SJ is an employee of AstraZeneca R\&D Mölndal, Sweden, and MAW was an employee of AstraZeneca R\&D Mölndal, Sweden at the time of the study. The corresponding author had full access to all the data in the study, and takes responsibility for the integrity of the data and the accuracy of the data analysis.

\section{Authors' contributions}

$\mathrm{CH}$ participated in the design of the study, carried out the statistical analysis, interpreted the data and helped to draft the manuscript. SJ and MAW participated in the design of the study and interpretation of the data. LAGR conceived of the study, participated in its design, analysis and interpretation and helped to draft the manuscript. All authors critically revised the manuscript for important intellectual content, and approved the final manuscript.

\section{Acknowledgements}

We thank the primary care physicians participating in the General Practice Research Database for their excellent collaboration. We also thank Christopher Winchester, DPhil, from Oxford PharmaGenesis Ltd, who provided editorial assistance, funded by AstraZeneca R\&D Mölndal, Sweden. This study was funded by AstraZeneca R\&D Mölndal, Sweden.

\section{References}

I. Prandoni P, Ghirarduzzi A, Prins $M H$, Pengo V, Davidson BL, Sorensen H, Pesavento R, lotti M, Casiglia E, Iliceto S, Pagnan A, Lensing AW: Venous thromboembolism and the risk of subsequent symptomatic atherosclerosis. J Thromb Haemost 2006, 4:189|-1896

2. Becattini C, Agnelli G, Prandoni P, Silingardi M, Salvi R, Taliani MR, Poggio R, Imberti D, Ageno W, Pogliani E, Porro F, Casazza F: A prospective study on cardiovascular events after acute pulmonary embolism. Eur Heart J 2005, 26:77-83.

3. Schulman S, Lindmarker P, Holmstrom M, Larfars G, Carlsson A Nicol P, Svensson E, Ljungberg B, Viering S, Nordlander S, Leijd B, jahed K, Hjorth M, Linder O, Beckman M: Post-thrombotic syndrome, recurrence, and death 10 years after the first episode of venous thromboembolism treated with warfarin for 6 weeks or 6 months. J Thromb Haemost 2006, 4:734-742.

4. Jick $\mathrm{H}$, Jick SS, Derby LE: Validation of information recorded on general practitioner based computerised data resource in the United Kingdom. BM] I991, 302:766-768.

5. Jick SS, Kaye JA, Vasilakis-Scaramozza C, Garcia Rodriguez LA, Ruigomez A, Meier CR, Schlienger RG, Black C, Jick H: Validity of the general practice research database. Pharmacotherapy 2003, 23:686-689.

6. Lawrenson R, Todd JC, Leydon GM, Williams TJ, Farmer RD: Validation of the diagnosis of venous thromboembolism in general practice database studies. Br J Clin Pharmacol 2000, 49:59l-596.

7. Jick H, Jick SS, Gurewich V, Myers MW, Vasilakis C: Risk of idiopathic cardiovascular death and nonfatal venous thromboembolism in women using oral contraceptives with differing progestagen components. Lancet 1995, 346: $1589-1593$. 
8. Vasilakis $\mathrm{C}$, Jick H, del Mar Melero-Montes M: Risk of idiopathic venous thromboembolism in users of progestagens alone. Lancet 1999, 354:1610-1611.

9. Perez Gutthann S, Garcia Rodriguez LA, Castellsague J, Duque Oliart A: Hormone replacement therapy and risk of venous thromboembolism: population based case-control study. Bmj 1997, 3 | 4:796-800.

10. Meier $\mathrm{CR}$, Jick $\mathrm{H}$ : Tamoxifen and risk of idiopathic venous thromboembolism. Br J Clin Pharmacol 1998, 45:608-6I2

11. Huerta C, Wallander MA, Johansson S, Garcia Rodriguez LA: Natural history of venous thromboembolism diagnosed in UK primary care. Arch Int Med in press.

12. White RH: The epidemiology of venous thromboembolism. Circulation 2003, 107:14-8.

13. Bova C, Marchiori A, Noto A, Rossi V, Daniele F, Santoro C, Ricchio $R$, De Lorenzo R, Umbaca R, Prandoni P: Incidence of arterial cardiovascular events in patients with idiopathic venous thromboembolism. A retrospective cohort study. Thromb Haemost 2006, 96:132-136.

14. Garcia Rodriguez LA, Varas-Lorenzo C, Maguire A, Gonzalez-Perez $A$ : Nonsteroidal antiinflammatory drugs and the risk of myocardial infarction in the general population. Circulation 2004, 109:3000-3006.

15. Volmink JA, Newton JN, Hicks NR, Sleight P, Fowler GH, Neil HA: Coronary event and case fatality rates in an English population: results of the Oxford myocardial infarction incidence study. The Oxford Myocardial Infarction Incidence Study Group. Heart 1998, 80:40-44.

16. Tunstall-Pedoe H, Kuulasmaa K, Amouyel P, Arveiler D, Rajakangas AM, Pajak A: Myocardial infarction and coronary deaths in the World Health Organization MONICA Project. Registration procedures, event rates, and case-fatality rates in 38 populations from 21 countries in four continents. Circulation 1994, 90:583-612.

17. Prandoni P, Bilora F, Marchiori A, Bernardi E, Petrobelli F, Lensing AW, Prins MH, Girolami A: An association between atherosclerosis and venous thrombosis. N Engl J Med 2003, 348: I 435- I 44I.

18. Hong C, Zhu F, Du D, Pilgram TK, Sicard GA, Bae KT: Coronary artery calcification and risk factors for atherosclerosis in patients with venous thromboembolism. Atherosclerosis 2005, 183:169-174.

19. Sørensen HT, Horvath-Puho E, Pedersen L, Baron JA, Prandoni P. Venous thromboembolism and subsequent hospitalisation due to acute arterial cardiovascular events: a 20-year cohort study. Lancet 2007, 370:1773-1779.

20. Heit JA, Silverstein MD, Mohr DN, Petterson TM, O'Fallon WM Melton LJ 3rd: Predictors of survival after deep vein thrombosis and pulmonary embolism: a population-based, cohort study. Arch Intern Med 1999, 159:445-453.

21. Ribeiro $A$, Lindmarker $P$, Johnsson $H$, Juhlin-Dannfelt $A$, Jorfeldt $L$ : Pulmonary embolism: one-year follow-up with echocardiography doppler and five-year survival analysis. Circulation 1999, 99:1325-1330.

22. Horlander KT, Mannino DM, Leeper KV: Pulmonary embolism mortality in the United States, 1979-1998: an analysis using multiple-cause mortality data. Arch Intern Med 2003, 163:1711-1717.

23. Prandoni P, Lensing AW, Cogo A, Cuppini S, Villalta S, Carta M, Cattelan AM, Polistena P, Bernardi E, Prins MH: The long-term clinical course of acute deep venous thrombosis. Ann Intern Med 1996, I 25: I-7.

24. Lee AY, Levine MN: Venous thromboembolism and cancer: risks and outcomes. Circulation 2003, 107:II7-2I.

25. Reich LM, Folsom AR, Key NS, Boland LL, Heckbert SR, Rosamond WD, Cushman M: Prospective study of subclinical atherosclerosis as a risk factor for venous thromboembolism. J Thromb Haemost 2006, 4:1909-1913.

26. Goldhaber SZ, Grodstein F, Stampfer MJ, Manson JE, Colditz GA, Speizer FE, Willett WC, Hennekens $\mathrm{CH}$ : A prospective study of risk factors for pulmonary embolism in women. JAMA 1997, 277:642-645.

27. Tsai AW, Cushman M, Rosamond WD, Heckbert SR, Polak JF, Folsom AR: Cardiovascular risk factors and venous thromboembolism incidence: the longitudinal investigation of thromboembolism etiology. Arch Intern Med 2002, 162:1182-1189.
28. van der Hagen PB, Folsom AR, Jenny NS, Heckbert SR, O'Meara ES, Reich LM, Rosendaal FR, Cushman M: Subclinical atherosclerosis and the risk of future venous thrombosis in the Cardiovascular Health Study. J Thromb Haemost 2006, 4: I 903-I 908.

29. Ageno W, Prandoni P, Romualdi E, Ghirarduzzi A, Dentali F, Pesavento $R$, Crowther $M$, Venco $A$ : The metabolic syndrome and the risk of venous thrombosis: a case-control study. J Thromb Haemost 2006, 4:1914-1918.

30. Jick H, Derby LE, Gurewich V, Vasilakis C: The risk of myocardial infarction associated with antihypertensive drug treatment in persons with uncomplicated essential hypertension. Pharmacotherapy 1996, 16:321-326.
Publish with Biomed Central and every scientist can read your work free of charge

"BioMed Central will be the most significant development for disseminating the results of biomedical research in our lifetime. "

Sir Paul Nurse, Cancer Research UK

Your research papers will be:

- available free of charge to the entire biomedical community

- peer reviewed and published immediately upon acceptance

- cited in PubMed and archived on PubMed Central

- yours - you keep the copyright 